\title{
Relationships between Fruit Acceptability and Health-Case of Seven Pomegranate (Punica granatum L.) Juices
}

\author{
Chiraz El Kar $^{1^{*}}$, Narjes Mtimet ${ }^{2}$, Ali Ferchichi ${ }^{1}$, Jalloul Bouajila ${ }^{2 *}$ \\ ${ }^{1}$ Laboratoire d'Aridoculture et de Cultures Oasiennes, Institut des Régions Arides, Médenine, Tunisie; ${ }^{2}$ Université de Toulouse, \\ Laboratoire des Interactions Moléculaires et Réactivité Chimique et Photochimique UMR CNRS 5623, Université Paul-Sabatier, \\ Toulouse, France. \\ Email: "echiraz@yahoo.fr, "bouajila@cict.fr
}

Received March 30 $0^{\text {th }}, 2013$; revised April 30 ${ }^{\text {th }}, 2013$; accepted May $7^{\text {th }}, 2013$

Copyright (C) 2013 Chiraz El Kar et al. This is an open access article distributed under the Creative Commons Attribution License, which permits unrestricted use, distribution, and reproduction in any medium, provided the original work is properly cited.

\begin{abstract}
The objective of this study was to evaluate acceptability and instrumental measurements (titratable acidity, total soluble sugar, total phenolic, flavonoids, anthocyanins, and condensed tannin contents as well as antioxidant capacity) of seven Tunisian pomegranate cultivars to relate fruit acceptability and beneficial health. Seventy one participants were asked to complete a questionnaire and to indicate their level of acceptance, on a nine point-hedonic scale, for fruit size, sweetness, bitterness, juice color and juice overall acceptability. Taste and aril color were the main criteria to select Pomegranate. Significant differences occurred for all the acceptability tests. Titratable acidity determines the taste and important inter-specific variability in the phenolic contents as well as for the antioxidant capacities was noticed. Anthocyanin and condensed tannin were contributing to the organoleptic properties while bitterness acceptability was negatively correlated to the antioxidant capacity. Also, a relationship was found between the fruit size acceptability and the antioxidant capacity.
\end{abstract}

Keywords: Pomegranate Juice; Acceptability Tests; Instrumental Measurements; Phenolic Contents; Antioxidant Capacity

\section{Introduction}

"The eyes are the gatekeeper to the mouth". Color was suggested to be the most influential quality factor, as consumers have expectations of overall quality based on color [1]. Most of the yellow, red and blue colors in fruit are related to the flavonoids [2]. Flavonoids are a group of polyphenolic compounds naturally present in a wide variety of fruit and vegetables. Fruit and vegetable consumption decreases the risks of coronary heart disease and lung cancer probably to their phenolic compounds [3].

Phenolics are secondary metabolites synthesized by plants, both during normal development and in response to stress conditions such as infection, wounding and UV radiation, among others [4]. In plants, phenolics may act as phytoalexins, antifeedants, attractants for pollinators, contributors to plant pigmentation, antioxidants and protective agents against UV light, among others. In food, phenolics may contribute to their organoleptic properties,

\footnotetext{
${ }^{*}$ Corresponding author.
}

such as, bitterness, astringency, color, flavor, odor and oxidative stability [5].

Among colored fruits, containing phenolics there is the Pomegranate [6,7]. The Pomegranate (Punica granatum L. Punicaceae) is a fruit becoming more popular because of its healthy properties [8]. These healthy properties come from the high antioxidant activity of the phenolic compounds content of the Pomegranate fruit $[8,9]$. However, it is surprising that the literature focused on the antioxidant properties of the phenolics but little is yet known about their contribution to the organoleptic properties of the Pomegranates.

Thus, the present study aims at relating the phenolic contents to the organoleptic properties of the Pomegranate juices as perceived by a panel of participants. To achieve this objective, a collection of seven Tunisian pomegranate cultivars differing in fruit internal color (from light pink to deep pink), taste (from sour-sweet to sweet) and fruit size (from small to large) was examined. The results were used to test for correlations between acceptability tests, physicochemical properties, phenolic con- 
tents and antioxidant capacity. This study allows identifying a possible link between the acceptability of Pomegranates and the protective effect of their phenolic compounds.

\section{Materials and Methods}

\subsection{Participants}

Seventy one adults, eligible and volunteers (40 men and 31 women) were recruited through ad wall in the Institute of Arid Regions of Medenin in Tunisia during the two last weeks of October 2008. Criteria for participation were: age from 18 to 55 years, regular consumer of pomegranate, no experience in sensory analysis, not being allergic to any food and availability for the test. Students and staff of the Institute of Arid Regions who work-ed on pomegranate were excluded in this study as it was thought they may affect the outcomes with their advanced skills on pomegranate taste. Participants reported their answers on individual ballots.

\subsection{Samples}

Seven Tunisian pomegranate cultivars differing in fruit size, juice color and juice taste were examined (Table 1). The fruits were classified as large when their diameter was superior to $95 \mathrm{~mm}$, they were medium if their diameter was from 75 to $95 \mathrm{~mm}$ and they were small when their diameter was inferior to $75 \mathrm{~mm}$. The juice color was determined visually while the juice taste was defined according to their sugar to acidity ratio [10]. A sugar to acidity ratio between 8 and 24 indicated sour-sweet cultivars, while a ratio from 25 to 98 referred to sweet cultivars. The cultivars included in the present study were chosen according to customary consumer purchasing practices and the answers to the questionnaire on perceptions and consumption of pomegranate. The denominations of the cultivars refer, in Tunisian, to the population where they belong or to the taste of the fruit [11]. The cultivars were selected from mature fruits grown in the collection of the Tunisian National Germplasm of pomegranate located at Zerkin $\left(33^{\circ} 45^{\prime} \mathrm{N}, 10^{\circ} 16^{\prime} \mathrm{E}\right)$ [11]. They were cultivated under homogenous conditions, without any special management (no fertilizers, no irrigation except natural rainfall). Approximately, fifteen $\mathrm{kg}$ of each cultivar were picked at harvesting maturity in the last week of September 2008 and in the last week of October 2008. According to Mirdehghan and Rahemi [12], the harvest maturity for pomegranate is achieved, when the arils' weight is greater than that of the peel. Fruits were transported by ventilated car to the laboratory, and trans-

Table 1. Codes, cultivars, main characteristics, mean value and standard deviations of instrumental analyses of the seven Tunisian Pomegranate (Punica granatum) studied.

\begin{tabular}{|c|c|c|c|c|c|c|c|c|c|c|c|c|c|}
\hline \multirow[b]{2}{*}{ Codes } & \multirow[b]{2}{*}{ Cultivars } & \multicolumn{3}{|c|}{ Main characteristics } & \multirow{2}{*}{$\begin{array}{c}\text { TSS } \\
\left({ }^{\circ} \text { Brix }\right)\end{array}$} & \multirow{2}{*}{$\begin{array}{l}\text { TA (\% } \\
\text { MA) }\end{array}$} & \multirow[b]{2}{*}{ TSS/TA } & \multirow[b]{2}{*}{$\mathrm{CD}$} & \multirow{2}{*}{$\begin{array}{c}\text { TPC } \\
(\mathrm{mgGAE} / \mathrm{L})\end{array}$} & \multirow{2}{*}{$\begin{array}{c}\mathrm{TFC} \\
(\mathrm{mgQE} / \mathrm{L})\end{array}$} & \multirow{2}{*}{$\begin{array}{c}\text { TAC } \\
(\mathrm{mgCGE} / \mathrm{L})\end{array}$} & \multirow{2}{*}{$\begin{array}{c}\mathrm{CTC} \\
(\mathrm{mgCE} / \mathrm{L})\end{array}$} & \multirow{2}{*}{$\begin{array}{c}\text { ABTS } \\
\mathrm{IC}_{50} \\
(\mathrm{mg} / \mathrm{L})\end{array}$} \\
\hline & & $\begin{array}{l}\text { Fruit } \\
\text { size }^{\mathrm{A}}\end{array}$ & $\begin{array}{l}\text { Juice } \\
\text { color }^{\mathrm{B}}\end{array}$ & $\begin{array}{l}\text { Juice } \\
\text { taste }^{\mathrm{C}}\end{array}$ & & & & & & & & & \\
\hline $\mathrm{CH} 4$ & Chelfi 4 & $\mathrm{~L}$ & LP & Sweet & $14.8 \pm 0.2$ & $0.2 \pm 0.01$ & $59.2 \pm 20$ & $0.3 \pm 0.01$ & $1073 \pm 44$ & $329 \pm 15$ & $93 \pm 3$ & $2070 \pm 0.1$ & $755 \pm 21$ \\
\hline KL 11 & Kalaii 11 & $\mathrm{~L}$ & $P$ & Sweet & $14.0 \pm 0.1$ & $0.5 \pm 0.02$ & $27.8 \pm 5$ & $0.5 \pm 0.01$ & $1075 \pm 30$ & $120 \pm 5$ & $188 \pm 7$ & $2826 \pm 0.1$ & $498 \pm 18$ \\
\hline GR 2 & $\begin{array}{c}\text { Garoussi } \\
2\end{array}$ & $\mathrm{~L}$ & DP & Sour-sweet & $16.5 \pm 0.2$ & $1.8 \pm 0.05$ & $9.2 \pm 4$ & $1.7 \pm 0.04$ & $413 \pm 21$ & $268 \pm 8$ & $20 \pm 1$ & $1436 \pm 0.1$ & $1073 \pm 22$ \\
\hline ZG 11 & $\begin{array}{c}\text { Zaghouani } \\
11\end{array}$ & M & $\mathrm{P}$ & Sweet & $14.5 \pm 0.1$ & $0.4 \pm 0.01$ & $36.2 \pm 10$ & $1.5 \pm 0.03$ & $1316 \pm 41$ & $679 \pm 21$ & $40 \pm 2$ & $2507 \pm 0.1$ & $638 \pm 21$ \\
\hline JB 1 & Jbeli 1 & M & DP & Sweet & $15.8 \pm 0.2$ & $0.4 \pm 0.01$ & $40.0 \pm 20$ & $0.8 \pm 0.01$ & $1382 \pm 62$ & $1100 \pm 32$ & $77 \pm 3$ & $2217 \pm 0.1$ & $492 \pm 17$ \\
\hline $\mathrm{CH} 2$ & Chelfi 2 & $\mathrm{~S}$ & LP & Sweet & $15.0 \pm 0.2$ & $0.5 \pm 0.02$ & $30.0 \pm 10$ & $1.0 \pm 0.02$ & $1232 \pm 31$ & $264 \pm 7$ & $25 \pm 1$ & $1458 \pm 0.1$ & $1342 \pm 33$ \\
\hline \multirow[t]{4}{*}{ NB 1} & Nabli 1 & $\mathrm{~S}$ & $\mathrm{P}$ & Sweet & $15.0 \pm 0.2$ & $0.4 \pm 0.01$ & $37.5 \pm 20$ & $0.6 \pm 0.01$ & $4570 \pm 185$ & $211 \pm 8$ & $433 \pm 23$ & $5299 \pm 0.2$ & $493 \pm 15$ \\
\hline & \multicolumn{4}{|c|}{ Mean } & $15.1 \pm 0.2$ & $0.6 \pm 0.02$ & $34.3 \pm 13$ & $0.9 \pm 0.02$ & $1580 \pm 59$ & $424 \pm 14$ & $125 \pm 6$ & $2545 \pm 0.1$ & $756 \pm 21$ \\
\hline & \multicolumn{4}{|c|}{ Relevant SD } & 0.8 & 0.5 & 15.0 & 0.5 & 1357 & 346 & 148 & 1317 & 333 \\
\hline & \multicolumn{3}{|c|}{ CV (\%) } & & 6 & 90 & 44 & 57 & 86 & 82 & 118 & 52 & 44 \\
\hline
\end{tabular}

All values are reported as \pm standard deviation; ${ }^{A}$ Fruit sizes were based on diameter measurements. Diameter $>95 \mathrm{~mm}=\mathrm{Large}$ fruit $(\mathrm{L}) ; 75 \mathrm{~mm}<$ diameter $<$ $95 \mathrm{~mm}=$ Medium fruit $(\mathrm{M})$; diameter $<75 \mathrm{~mm}=$ Small fruit $(\mathrm{S}) ;{ }^{\mathrm{B}}$ Juice color was visually determined. LP = Light Pink; P = Pink; DP = Dark Pink; ${ }^{\mathrm{C}}$ Taste was determined according to Melgarejo, Salazar \& Artés, (2000). $8<$ TSS/TA $<24=$ sour-sweet cultivars; $25<$ TSS/TA $<98=$ sweet cultivars; TSS = Total Soluble Sugars expressed as degrees Brix ( ${ }^{\circ}$ Brix); TA = Titratable Acidity expressed as pourcent of malic acid $(\% \mathrm{MA})$; TSS/TA = sugars to acidity ratio; CD = Color Density; TPC = Total Phenolic Content expressed as mg gallic acid equivalent per liter of juice (mg GAE/L); TFC = Total Flavonoids Content expressed as $\mathrm{mg}$ quercetin equivalent per liter of juice $(\mathrm{mg} \mathrm{QE} / \mathrm{L})$; TAC $=$ Total Anthocyanins Content expressed as mg cyaniding-3-glucoside equivalent per liter of juice $(\mathrm{mg} \mathrm{CGE} / \mathrm{L}) ; \mathrm{CTC}=$ Condensed Tannins Content expressed as mg catechin equivalent per liter of juice $(\mathrm{mg}$ CE/L); ABTS IC $50=$ radical scavenging capacity on ABTS radical expressed as concentration of the extract required to reduce $50 \%$ of the initial ABTS free radical; Relevant $\mathrm{SD}=\mathrm{Relevant}$ standard deviation; $\mathrm{CV}=$ coefficient of Variation $=$ Relevant SD to mean in percent. 
ferred to a $4^{\circ} \mathrm{C}$ store room on the same day as they were harvested. To avoid possible contamination of the juices with the metabolites produced by microorganisms, fruits with cracks, cuts, sunburn and other defects in husk were disposed of and only healthy fruits of uniform size and appearance were arranged in one row in wooden boxes containing packing material during the experiments. Whole fruits were preserved for the fruit size acceptability while others were squeezed to juices for further analysis. For thus, fruits for each cultivar were manually peeled, ground in a commercial turmix blender (Moulinex) for $30 \mathrm{~s}$, and filtered through muslin cloth $(0.5 \mathrm{~mm})$. The homogenate juices obtained were freshly utilized for physico-chemical analyses and acceptability tests.

\subsection{Sensory Analyses}

\subsubsection{Questionnaire}

Participants were asked to complete a one-page questionnaire (Table 2) developed and administered by the author, on their consumption of Pomegranate. The questionnaire included three types of questions: 1) eat, 2) purchase and 3) medicinal effects. For each question, participants indicated their responses by a cross in front of the answer(s) corresponding to their choice. Each participant indicated his answer(s) on an individual questionnaire.

\subsubsection{Acceptability Tests}

Prior to the acceptability tests, participants were given a presentation outlining the methodology and the procedure of the sensory methods.

Participants evaluated the samples in one session (30 minutes). They were asked to assess, in a first time, the acceptability of the fruit size and the juice color, and, in a second time, to assess the acceptability of sweetness, bitterness and juice overall acceptability. The assessments were done by using a nine-point hedonic scale, where $1=$ dislike extremely, 2 = dislike very much, 3 = dislike moderately, $4=$ dislike slightly, $5=$ neither like nor dislike, $6=$ like slightly, $7=$ like moderately, $8=$ like very much and $9=$ like extremely [13]. The samples were presented with 3-digit codes in a balanced order to account for first order and carry-over effects [14]. The whole washed fruits were placed on white plates and the juices were presented in transparent glasses at room temperature. The assessments were done in a well ventilated and at

Table 2. Questionnaire on perceptions and consumption of pomegranate $(N=71)$.

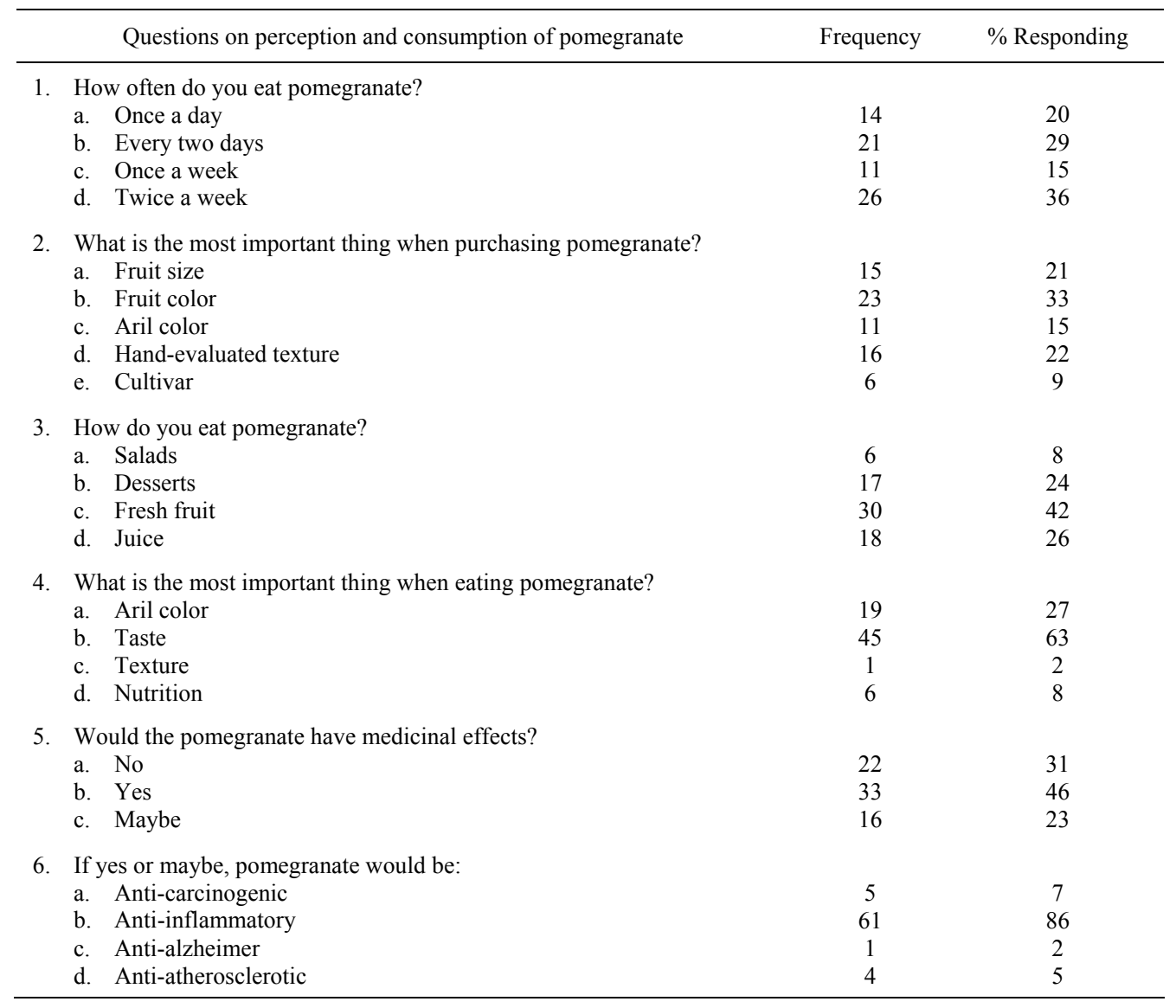


ambient temperature room of the Institute of Arid Regions. Participants were provided with mineral water, unsalted crackers, and expectorant cups to cleanse the palate between sample evaluations. They were instructed to pause for one min between samples.

\subsection{Instrumental Analyses}

All chemicals used were of analytical reagent grade. All reagents were purchased from Sigma-Aldrich-Fluka (SaintQuentin France).

\subsubsection{Physico-Chemical Properties}

Titratable Acidity (TA) was determined by potentiometry, using a $\mathrm{pH}$ meter, with a $0,1 \mathrm{~N} \mathrm{NaOH}$ solution to a $\mathrm{pH}$ of 8.1. The results were expressed as percentage of Malic Acid (\%MA). A hand refractometer type OPTECH K7 1319 (Optical Technology, Munich, Germany) graduate of $0^{\circ}-32^{\circ}$ Brix was used to determine the Total Soluble Solids (TSS). Results were expressed in degrees Brix ( ${ }^{\circ}$ Brix). The sugar to acidity ratio (TSS/TA) was calculated using the relation between Total Soluble Solids by Acidity. Color Density (CD) was determined by measuring the absorbance at 420, 520 and $620 \mathrm{~nm}$ in a cell of 1 mm using a spectrophotometer Shimadzu (Shimadzu Corporation, Kyoto, Japan) UV-1201.

\subsubsection{Phenolics Content}

The phenolics of each fruit extract were determined by the method of Georgé et al. [15]. The diluted aqueous solution of each extract $(0.5 \mathrm{~mL})$ was mixed with Folin Ciocalteu reagent $(0.2 \mathrm{~N}, 2.5 \mathrm{~mL})$. The mixture was allowed to stand at room temperature for $5 \mathrm{~min}$ before adding sodium carbonate solution $(75 \mathrm{~g} / \mathrm{L}$ in water, $2 \mathrm{~mL})$. An hour later, the absorbances were measured at $765 \mathrm{~nm}$ against a water blank. A standard calibration curve was plotted using gallic acid $(0-300 \mathrm{mg} / \mathrm{L})$. The results were expressed as $\mathrm{mg}$ of gallic acid equivalents (GAE)/L of juice.

\section{1) Flavonoids Content}

The flavonoids were estimated according to the Dowd method as adapted by Arvouet-Grand, et al. [16]. A diluted methanolic solution $(4 \mathrm{~mL})$ of each plant extract was mixed with a solution $(4 \mathrm{~mL})$ of aluminium trichloride $\left(\mathrm{AlCl}_{3}\right)$ in methanol $(2 \%)$. The absorbance was read at $415 \mathrm{~nm}$ after $15 \mathrm{~min}$ against a blank sample consisting of methanol $(4 \mathrm{~mL})$ and plant extract $(4 \mathrm{~mL})$ without $\mathrm{AlCl}_{3}$. Quercetin was used as reference compound to produce the standard curve. The results were expressed as mg of quercetin equivalents $(\mathrm{QE}) / \mathrm{L}$ of juice.

2) Anthocyanins Content

Total anthocyanin contents were measured with the $\mathrm{pH}$ differential absorbance method, as described by Cheng and Breen [17]. Briefly, absorbance of the extract was measured at 510 and $700 \mathrm{~nm}$ in buffers at $\mathrm{pH} 1.0$ (hydrochloric acid-potassium chloride, $0.2 \mathrm{M}$ ) and 4.5 (acetic acid-sodium acetate, $1 \mathrm{M}$ ). The wavelength reading was performed after $15 \mathrm{~min}$ of incubation. Anthocyanin contents were calculated using a molar extinction coefficient $(\varepsilon)$ of 29600 (cyanidin-3-glucoside) and absorbance of $\mathrm{A}=\left[\left(\mathrm{A}_{510}-\mathrm{A}_{700}\right)_{\mathrm{pH} 1.0}-\left(\mathrm{A}_{510}-\mathrm{A}_{700}\right)_{\mathrm{pH} 4.5}\right]$. Results were expressed as $\mathrm{mg}$ cyanidin-3-glucoside equivalents/ L of juice.

\section{3) Tannins Content}

Proanthocyanidins reactive to vanillin were analyzed by the vanillin method [18]. One milliliter of extract solution was placed in a test tube together with $2 \mathrm{~mL}$ of vanillin $\left(1 \%\right.$ in $\left.7 \mathrm{M} \mathrm{H}_{2} \mathrm{SO}_{4}\right)$ in an ice bath and then incubated at $25^{\circ} \mathrm{C}$. After $15 \mathrm{~min}$, the absorbance of the solution was read at $500 \mathrm{~nm}$. Concentrations were calculated as $(+)$-catechin $(\mathrm{mg} / \mathrm{L}$ of juice) from a calibration curve.

\subsubsection{Antioxidant Capacity}

Antioxidant capacity was measured using the improved ABTS method. The radical scavenging capacity of antioxidants for the ABTS (2, 2'-azinobis-3-ethylbenzothiazoline-6-sulphonate) radical cation was determined as described by Re et al. [19]. ABTS radical was generated by mixing a $7 \mathrm{mM}$ of ABTS at pH $7.4\left(5 \mathrm{mM} \mathrm{NaH}_{2} \mathrm{PO}_{4}\right.$, $5 \mathrm{mM} \mathrm{Na}_{2} \mathrm{HPO}_{4}$ and $154 \mathrm{mM} \mathrm{NaCl}$ ) with $2.5 \mathrm{mM}$ potassium persulfate (final concentration) followed by storage in the dark at room temperature for $16 \mathrm{~h}$ before use. The mixture was diluted with ethanol to give an absorbance of $0.70 \pm 0.02$ units at $734 \mathrm{~nm}$ using Helios Alpha spectrophotometer (Thermospectronic, USA). For each sample, the diluted methanol solution of the extract $(100 \mu \mathrm{L})$ was allowed to react with fresh ABTS solution $(900 \mu \mathrm{L})$, and then the absorbance was measured 6 minutes after initial mixing. Ascorbic acid was used as a standard and the capacity of free radical scavenging was expressed by $\mathrm{IC}_{50}(\mathrm{mg} / \mathrm{L})$. Values calculated denote the concentration required to scavenge $50 \%$ of ABTS radical.

\subsection{Statistical Analysis}

All measurements were expressed as mean \pm standard deviation of triplicate measurements. Standard deviations (SD) did not exceed 5\% for the majority of the values obtained. Acceptability data was collected manually on a MS Excel spreadsheet and was recorded with "dislike extremely" equal to one, "like extremely" equal to nine, and intermediate points numbered appropriately. Analysis of Variance (ANOVA) was performed on the qualitative data obtained from the acceptability tests with $\alpha$ set at 0.05 . Friedman's test [20], employing a significance level of $\alpha<0.05$, was applied to the results of the hedonic test, to separate the means of the acceptability tests. Standardized Principal Component Analysis (PCA) was per- 
formed on the mean ratings among the participants for all acceptability tests. Hierarchical cluster analysis (HCA) with the Ward criteria was applied on the first two principal components of the PCA [21]. To compare the variability in quantitative physico-chemical composition of the samples having different averages and expressing in different units, the coefficient of variation (CV) was used. It expresses the standard deviation as a percentage of the mean. The data will be considered homogeneous if the $\mathrm{CV}$ is less than $15 \%$, and conversely, the data will be considered heterogeneous if the CV is greater than $15 \%$.A Pearson correlation analysis was carried out between the instrumental measurements with a $95 \%$ significance level. A Partial Least Square (PLS) regression analysis was performed to relate the acceptability data (Y-variables) to the instrumental data (X-variables). Regression coefficients for the relations between variables revealed by the PLS regression were estimated by jack-knifing, and significance levels were determined. All the data were collected in spread sheets and the statistical analyses were done using MS Excel Xlstat 2009 (Addinsoft, New York).

\section{Results and Discussion}

\subsection{Questionnaire}

The participants were asked to complete a questionnaire (Table 2) about their perceptions and consumptions of pomegranate. The external sensory attributes, such as appearance, color, size and hand-evaluated texture, which are evaluated by the consumer prior to consumption, are intrinsic quality cues. Taste and oral texture evaluated at the time of consumption are experience-quality attributes.

Among intrinsic quality cues, appearance (fruit size and fruit color) was the major factor (one of two) in the purchase of pomegranate fruits for the participants. Of all appearance factors, fruit color (one of three) was suggested to be the most influential quality factor, as participants have expectations of overall quality based on color, while fruit size (one of five) was considered to have minor influence on the consumer evaluation of Pomegranate quality. To our knowledge, no study was conducted on the intrinsic quality cues of pomegranates. Nevertheless, according to Kays [1], color was suggested to be the most influential quality factor, as participants have expectations of overall quality based on color, such as color cues for banana ripeness. The same author notes that at times, color expectations of quality may not be valid because, for example, some orange (Citrus spp.) cultivars are at their optimum when they are green, not orange as most participants perceive.

When experience-quality attributes, participants may be intending to consume pomegranate because of its beneficial health consequences (one of ten), but taste (two of three) and aril color (two of seven) were the fundamental quality that must be satisfied for continued consumption. According to Kays [1], taste is ranked more highly than texture and appearance as a contributor to overall liking for food products; however, color and texture of horticultural products are more frequently cited as consumer quality attributes. Also, pomegranates were preferred as fresh fruit (three of seven) and juice (one of four). These results confirm those of Marlette [22], who found that apple sauce was preferred to whole apples. Thus, fruits would be preferred if they required no preparation, were ready-to-eat or not too difficult to eat.

Results from this study show that the size of the fruit, the taste, the color of the arils and the consumption of the Pomegranate as fresh fruit were the main criteria for participants to select and consummate pomegranate. Thus, these criteria were considered to select the plant material. In order to homogeneity experimental conditions, pomegranate juices were used also for the acceptability tests and the instrumental analyses.

\subsection{Acceptability Tests}

As seen in Table 3, significant differences $(p<0.05)$ existed among pomegranate juices for all the acceptability tests. The participants liked most of the pomegranate juices (as indicated by mean scores $>5$ ) and the average scores for the pomegranate juices were particularly high. Also, participants preferred the juices from the cultivars CH 2 and NB 1 and the cultivar JB 1 received the highest score for juice color acceptability.

To determine the relationships between the juice over-

Table 3. Mean scores $(n=71)$ for acceptability tests of the seven Tunisian Pomegranate (Punica granatum) cultivars studied $^{\mathrm{A}}$.

\begin{tabular}{cccccc}
\hline Cultivars & Fruit size & Juice color & Sweetness & Bitterness & $\begin{array}{c}\text { Juice overall } \\
\text { acceptability }\end{array}$ \\
\hline $\mathrm{CH} 2$ & $6.42^{\mathrm{b}}$ & $5.98^{\mathrm{a}}$ & $7.94^{\mathrm{ab}}$ & $2.06^{\mathrm{a}}$ & $7.20^{\mathrm{ab}}$ \\
$\mathrm{CH} 4$ & $7.85^{\mathrm{b}}$ & $5.23^{\mathrm{a}}$ & $4.57^{\mathrm{ab}}$ & $4.01^{\mathrm{a}}$ & $6.20^{\mathrm{ab}}$ \\
$\mathrm{GR} 2$ & $7.02^{\mathrm{b}}$ & $5.14^{\mathrm{a}}$ & $3.10^{\mathrm{ab}}$ & $5.29^{\mathrm{a}}$ & $4.75^{\mathrm{ab}}$ \\
$\mathrm{JB} 1$ & $5.04^{\mathrm{b}}$ & $7.82^{\mathrm{a}}$ & $4.00^{\mathrm{ab}}$ & $3.57^{\mathrm{a}}$ & $5.00^{\mathrm{ab}}$ \\
$\mathrm{KL} 11$ & $8.14^{\mathrm{b}}$ & $1.34^{\mathrm{a}}$ & $4.71^{\mathrm{ab}}$ & $4.17^{\mathrm{a}}$ & $5.83^{\mathrm{ab}}$ \\
$\mathrm{NB} 1$ & $4.81^{\mathrm{b}}$ & $4.02^{\mathrm{a}}$ & $6.29^{\mathrm{ab}}$ & $1.43^{\mathrm{a}}$ & $6.71^{\mathrm{ab}}$ \\
ZG 11 & $5.76^{\mathrm{b}}$ & $3.94^{\mathrm{a}}$ & $4.96^{\mathrm{ab}}$ & $4.63^{\mathrm{a}}$ & $4.56^{\mathrm{ab}}$ \\
\hline
\end{tabular}

${ }^{\mathrm{A}} \mathrm{S}$ cores were based on a nine-point hedonic scale with 1 = dislike extremely; $5=$ neither like nor dislike; and $9=$ like extremely. ${ }^{\text {a-b }}$ Means with different letters within each line indicate significant differences at $\mathrm{p}<0.05$ (Friedman test). 
all acceptability of the seven cultivars and the acceptability of the sweetness, the bitterness, the juice color and the fruit size, a PCA was performed. Principal Components 1 (PC1) and 2 (PC2) accounted for $55 \%$ and $30 \%$ of the total variance, respectively. As shown in Figure 1, it seems that participants have clearly distinguished cultivars from each other, since the products were dispersed in the space of the representation. To improve the interpretation of the PCA map, a HCA on the PC1 and PC2 was performed. Three classes of cultivars were revealed (Figure 2). A first class, named liked, includes the cultivars $\mathrm{CH} 2$ and NB 1. A second class corresponds to the neither liked nor disliked cultivars, such as, $\mathrm{CH} 4$ and $\mathrm{KL} 11$ and a third class, namely, disliked, was composed of the cultivars GR 2, JB 1 and ZG 11. By representing the three classes of cultivars on the PCA biplot, the liked class was closest to the juice overall acceptability and the acceptability of the sweetness. The neither liked nor disliked and the disliked classes seem to be grouped with the bitterness and diametrically opposed to the juice overall acceptability.

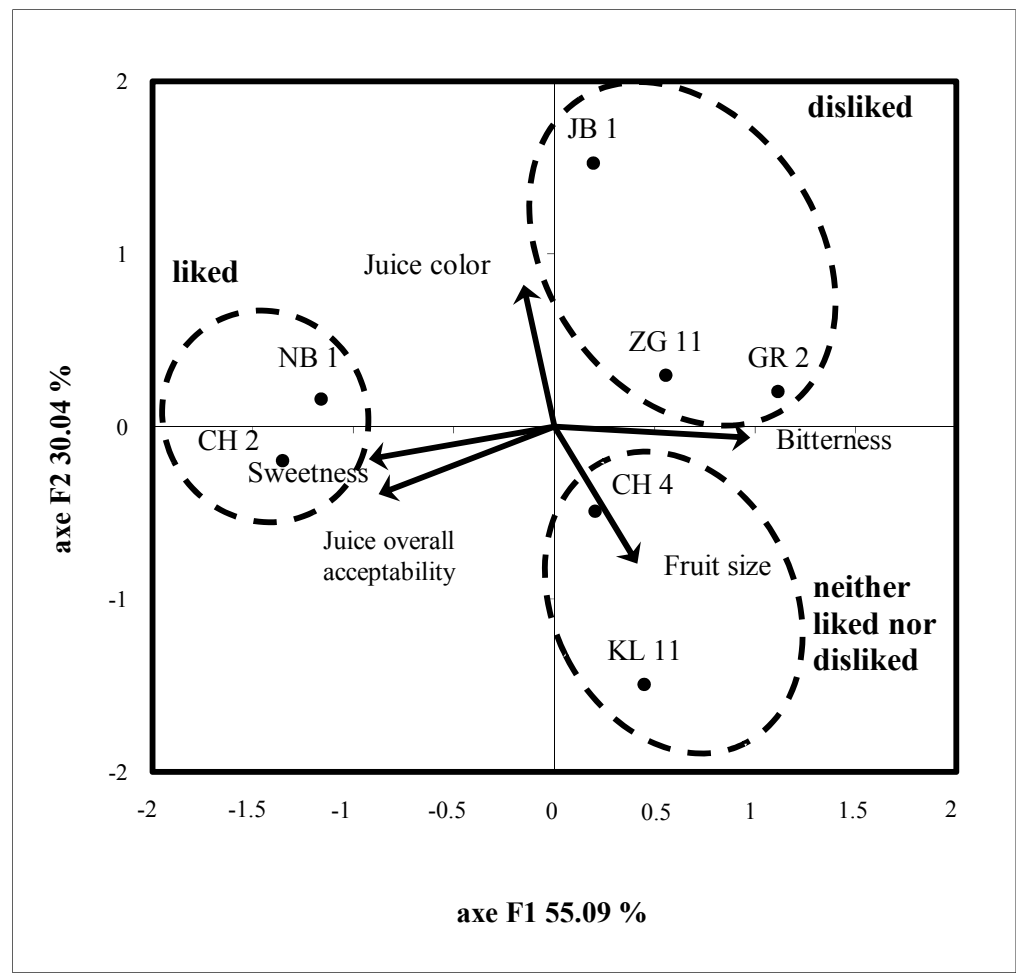

Figure 1. PCA map of consumer acceptability of the seven Tunisian Pomegranate (Punica granatum) cultivars studied. Forms dashed represent the three classes of cultivars defined by the HCA.

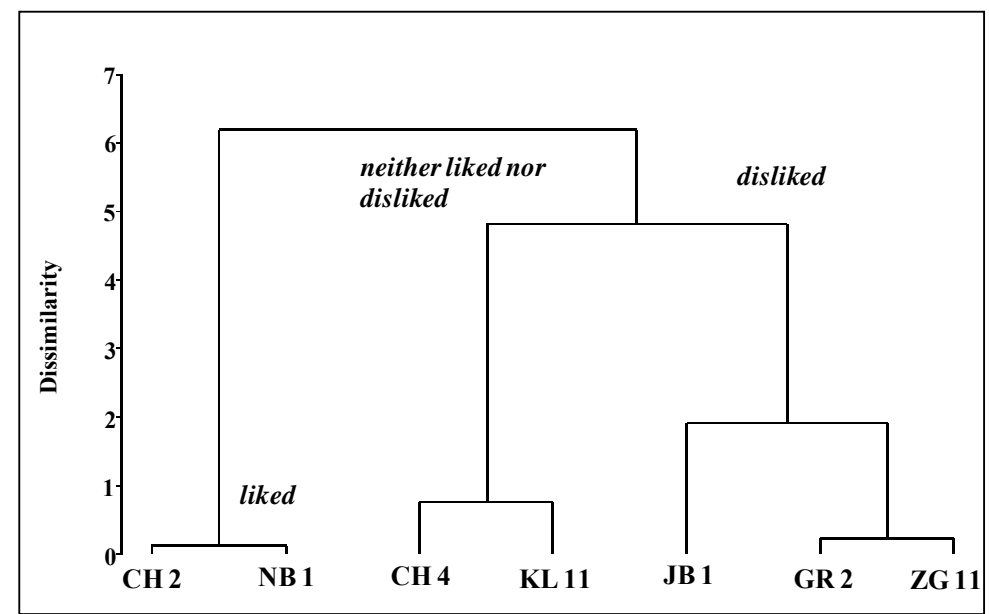

Figure 2. Dendrogram obtained by HCA on the first two principal components of the PCA. 
Although, the significant negative correlation $(\mathrm{R}=$ $-0.82, p<0.05)$ found between the sweetness and the bitterness acceptability explains the natural opposition between the two attributes. Also, the significant correlations found between the juice overall acceptability and the bitterness acceptability on one side $(\mathrm{R}=-0.83, \mathrm{p}<$ $0.05)$, and the sweetness acceptability $(\mathrm{R}=0.82, \mathrm{p}<$ 0.05 ), on the other, confirmed that heightened perception of bitterness was the principal reason for food rejection [23]. Other significant differences, less expected, were found. In fact, Friedman's test indicated highly significant differences $(p<0.05)$ between fruit size and juice color acceptability, in a hand, and fruit size and bitterness acceptability, in another hand. There is no report, to our knowledge, on the consumer acceptability of Pomegranate.

Thus, it can be concluded that the sweetness accounted for most of the variation in overall acceptability and the consumer rejection of the pomegranate juices was mainly related to the bitterness rather than to the color of juice or the fruit size.

\subsection{Physico-Chemical Properties}

Table 1 shows the average value and the standard deviations for the physico-chemical properties of the seven pomegranate juices analyzed. As seen, the pomegranate juices differed little in TSS $(\mathrm{CV}=6 \%)$ with values ranging from $14.0{ }^{\circ}$ Brix for the cultivar $\mathrm{CH} 4$ to $16.5^{\circ}$ Brix for the cultivar GR 2. However, great differences $(\mathrm{CV}=$ $90 \%$ ) were observed in TA with values ranging from $0.2 \% \mathrm{MA}$ for the cultivar $\mathrm{CH} 2 \%$ to $1.8 \% \mathrm{MA}$ for the cultivar GR 2. The TSS/TA ratio gives an indication of the sweetness of fruits. The higher the TSS/TA ratio, the sweeter is the fruit. With the highest values for TA and TSS, GR 2 was the sourness cultivar $(\mathrm{TSS} / \mathrm{TA}=9.2)$ while with lowest values for TA and TSS, CH 2 was the sweetness cultivar (TSS/TA = 59.2). The TSS of the studied cultivars was close to $15.1{ }^{\circ}$ Brix, both sweet and sour-sweet, thus, the TA was the factor which determines the taste of the Pomegranate. This result was confirmed by the significant negative correlation $(\mathrm{R}=-0.85, \mathrm{p}<$ 0.05 ) found between the TSS/TA ratio and the TA. So, it can be concluded that the taste of the pomegranate juices is inversely related to their TA. Similar conclusion was advanced for orange [24]. Table 1 shows also that there were great differences $(\mathrm{CV}=57 \%)$ with respect to the instrumental measurement of color of the pomegranate juices. Juice from the cultivar $\mathrm{CH} 2$ was differentiated as the lighter sample $(\mathrm{CD}=0.3)$ while juice from the cultivar GR 2 was the darkest $(C D=1.7)$ one; NB 1 cultivar presented intermediate values of lightness $(C D=1.0)$. The higher $\mathrm{CD}$ of the pomegranate juices could be explained by the heat units accumulated (difference be- tween the daily average temperature and $25^{\circ} \mathrm{C}$ ) prior to harvest. Indeed, the intensity of the red color of fresh Israeli pomegranate arils was found to be inversely related to the sum of heat units accumulated during fruit development and ripening [25].

\subsection{Phenolic Contents}

As shown in Table 1, the Total Polyphenols Content (TPC) varied greatly $(\mathrm{CV}=86 \%)$ among the seven cultivars, and the juice of the cultivar ZG 11 was characterized by the highest TPC with $4570 \mathrm{mg}$ GAE/L, while the lowest TPC was found in the juice of the cultivar GR 2 with $413 \mathrm{mg} \mathrm{GAE} / \mathrm{L}$. Özgen, et al. [6] reported a TPC ranging between 1245 and $2076 \mathrm{mg} \mathrm{GAE} / \mathrm{L}$ for six pomegranate varieties grown in the Mediterranean region of Turkey and Sepúlveda et al. [7] found a TPC from 676 to $1236 \mathrm{mg} \mathrm{GAE} / \mathrm{L}$ for ten different genotypes of Chilean pomegranate juices. Indeed, phenolic levels increase during exposure to biotic and abiotic stresses, such as wounding, drought, metal toxicity and nutrient deprivation and the highest values of phenolics corresponded to the varieties most sensitive to drought stress [4]. Hence, it can be deduced that the cultivar ZG 11 was the most sensitive to drought stress. This cultivar could be a good source of phenolics.

One of the important quality factors of pomegranate marketing is color. Dietary flavonoids are polyphenolic compounds responsible for the orange, red and blue colors in fruits and vegetables [2]. Also, anthocyanins are a largest group of flavonoids known to intervene in the color of the pomegranate juices [9]. So, Total Flavonoid Content (TFC) and Total Anthocyanin Content (TAC) were measured (Table 1). Besides, the cultivar KL 11 exhibited the highest TFC (1100 mg QE/L) while the highest TAC was found in the cultivar ZG $11(433 \mathrm{mg}$ CGE/L). When consumed regularly, these juices may contribute a significant amount of flavonoid to the diet. Ames [3] suggested that the consumption of flavonoidrich foods protects against human diseases associated with oxidative stress, like cancer. Also, variability among cultivars was greatest for the TFC $(\mathrm{CV}=82 \%)$ and TAC $(\mathrm{CV}=118 \%)$. However, the TAC found in this study (20 - $433 \mathrm{mg} \mathrm{CGE/L),} \mathrm{was} \mathrm{three} \mathrm{to} \mathrm{ten} \mathrm{times} \mathrm{greater} \mathrm{than} \mathrm{this}$ reported by Özgen, et al. [6] (6 - $41 \mathrm{mg}$ CGE/L) for six Turkey pomegranate juices. On the other hand, Sepúlveda et al. [7] founded a TAC around 676 to $1236 \mathrm{mg}$ CGE/L for ten Chilean pomegranate juices. In fact, the variability in the TAC could be explained by the climatic conditions. The extreme temperatures may decrease anthocyanin content by accelerating degradation [26].

Although, Tibe et al. [27] described a relationship between condensed tannin content and color. Thus, the 
Condensed Tannins Content (CTC) was determined. The pomegranate juices studied exhibited a $\mathrm{CV}$ of $52 \%$ and the cultivar ZG 11 was characterized by the highest CTC (5299 mg CE /L). Gil et al. [9] found a CTC of $417 \mathrm{mg} / \mathrm{L}$ for juice of "Wonderful" pomegranate variety of California while Mousavinejad, et al. [28] reported that the "Sweet Aalak" Iranian cultivar showed a tannin contents of $320 \mathrm{mg} / \mathrm{L}$ juice in comparison to the seven other cultivars studied. However, in other species, such as cowpea, Tibe, et al. [27] found that brown colored seeds of cowpeas contain more tannins than cream colored seeds. Therefore, it is not surprising that, the cultivar GR 2 with a red juice color had less tannin than other light colored cultivars in this study. It was unexpected; however, that the cultivar JB 1, with red juice color had a relatively high CTC which may be specific to this cultivar.

When a Pearson correlation was carried out with individual instrumental measurements, a high significant positive correlation $(\mathrm{R}=0.91, \mathrm{p}<0.05)$ was found between the TPC and the TAC; this suggests that the pomegranates studied are anthocyanin-rich fruits. Another high significant positive correlation $(\mathrm{R}=0.97, \mathrm{p}<0.05)$ was found between TAC and CTC. This result supports earlier studies [29] that found that anthocyanins and condensed tannins are related through a common biochemical pathway. So, it is important to consider the TAC and the CTC to balance pomegranate juice color.

By studying antioxidant activity of pomegranate juice and its relationship with phenolic composition and processing, Gil et al. [9] concluded that the variations in the phenolic composition may be due to differences among varieties and also, to maturity, horticultural practices, geographic origin, growing season, postharvest storage conditions and processing procedures. To deepen the knowledge on the variation of the phenolic composition of pomegranate juice, the climatic and edaphic influences were limited, as well as, the horticultural practices by collecting the pomegranates from the same site where the culture conditions were homogenous, without fertilizers and irrigation. Also, the postharvest storage conditions of the pomegranate and the processing procedures for the determination of the phenolic composition were the same. So, it can be concluded that the observed differences in terms of phenolic contents of the juices depend on cultivar type or/and ripening season.

\subsection{Antioxidant Capacity}

The results from free radical scavenging revealed that pomegranate juices differed $(\mathrm{CV}=44 \%)$ in their antioxidant capacities. Relatively high levels of TPC were observed in ZG 11 and KL 11 cultivars, so they decreased capacity toward ABTS radical scavenging. The hierarchy for antioxidant capacity was KL $11>\mathrm{ZG} 11>\mathrm{CH} 4>$
JB $1>$ CH $2>$ GR $2>$ NB 1. Also, antioxidant capacity of the cultivar KL 11 was about three times higher than that of the cultivar NB 1. An antioxidant, which can quench reactive free radicals, can prevent the oxidation of other molecules and may have, therefore, health-promoting effects in the prevention against diseases linked to oxidative stress. Thus, the juices of KL 11 and ZG 11 cultivars may be considered as a source of natural antioxidants for drug products because of their high antioxidant capacity. These results confirm previous works $[6$, $9,30]$ about the antioxidant activity of pomegranate juices.

In the present study, phenolic contents were not significantly correlated with antioxidant activity in the ABTS assay. However, the results of exhaustive work of two groups $[9,30]$ on antioxidant activity of pomegranate juices suggested that anthocyanins play only a minor role in this activity. Thus, it can be concluded that the flavonoids, including anthocyanins, and condensed tannins play a minor role in the antioxidant activity of the pomegranate juices studied. Nevertheless, Seeram et al. [8] found that synergism between the antioxidants in a mixture makes the antioxidant activity not only dependent on the concentration, but also on the structure and the interaction between the antioxidants.

\subsection{Correlation between Consumer Acceptability Tests and Instrumental Analyses}

The PLS regression analysis carried out to relate the five acceptability tests (variables $\mathrm{Y}$ ) to the nine instrumental analyses (variable $\mathrm{X}$ ), leads to the map shown in Figure 3. With a global $R^{2}$ between $Y$ and $\left(t_{1}, t_{2}\right)$ equal to 0.45 , the quality of the regression was low. Also, Figure 3 shows that fruit size and juice color acceptability cannot be related to pomegranate characteristics since they are located in the centre of the graphical display. Therefore, it does not seem useful to take this acceptability into account. Similarly, it seems that TFC doesn't play an important role in explaining the consumer acceptability of the pomegranate. Therefore, these variables were removed from the analysis. In this approach, a new PLS regression was carried out. The quality of the new PLS regression was noticeable higher than the previous one $\left(\mathrm{R}^{2}=\right.$ 0.71). By comparing the new map (figure not shown) obtained with the previous one, it can be noticed that the new map is an extract of the Figure 3. This confirms the stability and the robustness of the PLS regression analysis.

As shown in Figure 4, the sweetness acceptability appeared significantly positively correlated to the $\mathrm{CD}$. Also, the acceptability of bitterness was significantly positively correlated to the TAC. In fact, Zampini, et al. [31], found 


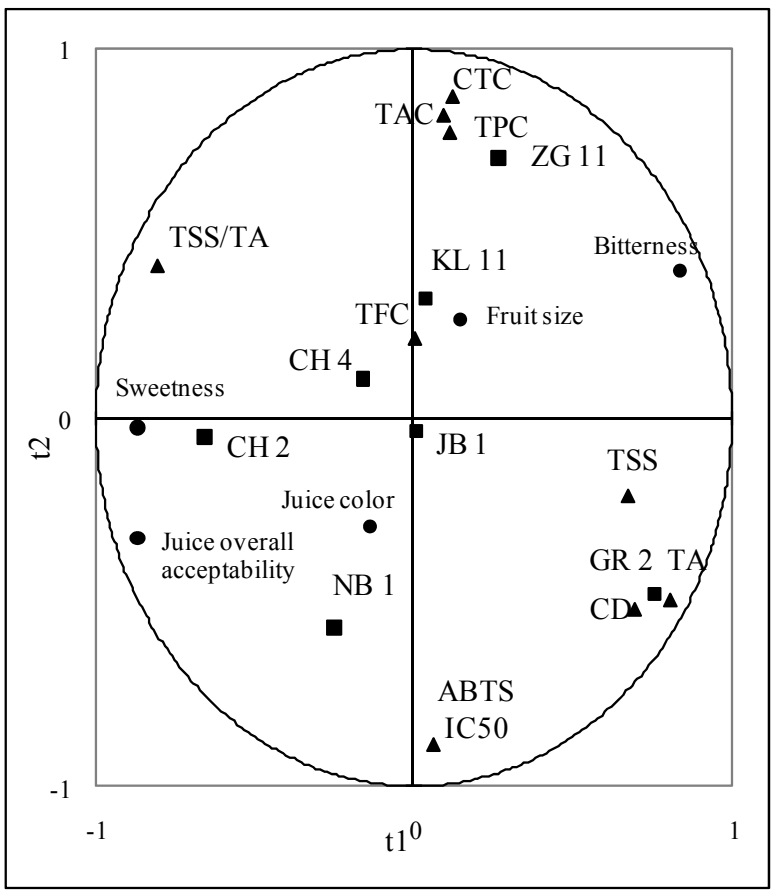

Figure 3. Partial Least Squares regression map showing the correlation between consumer acceptability data and instrumental data in the seven Pomegranates studied $(\square=$ cultivars as indicated in Table $2 ; \bullet=$ acceptability attributes; $\Delta$ = instrumental variables; TSS $=$ Total Soluble Sugars expressed as degrees Brix ( ${ }^{\circ}$ Brix); TA $=$ Titratable Acidity expressed as pourcent of malic acid (\% MA); TSS/TA $=$ sugars to acidity ratio; $\mathbf{C D}=$ Color Density; $\mathbf{T P C}=$ Total Phenolic Content expressed as mg gallic acid equivalent per liter of juice $(\mathrm{mg}$ GAE/L); TFC = Total Flavonoids Content expressed as mg quercetin equivalent per liter of juice (mg $\mathrm{QE} / \mathrm{L}) ; \mathrm{TAC}=$ Total Anthocyanins Content expressed as mg cyaniding-3-glucoside equivalent per liter of juice (mg CGE/L); CTC $=$ Condensed Tannins Content expressed as mg catechin equivalent per liter of juice (mg CE/L); ABTS $\mathrm{IC}_{50}=$ radical scavenging capacity on ABTS radical expressed as concentration of the extract required to reduce $50 \%$ of the initial ABTS free radical).

a significant main effect of flavor on color. Indeed, they revealed that orange-colored solutions were rated as sweeter when they had an orange flavor than when they were flavorless, thus color cues might exert a stronger influence on people's flavor identification responses. Acceptability of bitterness was also significantly negatively correlated to the antioxidant capacities. However, cancer researchers even proposed that heightened bitterness might be a positive feature, allowing consumers to select broccoli sprouts with the highest glucosinolate content [32]. As was also indicated in Figure 4, the juice overall acceptability was correlated to the CTC. Previous studies have shown that condensed tannins contribute to the bitterness taste of fruits [23]. The correlations between TAC, $\mathrm{CTC}$ and, respectively, bitterness and juice overall accep- tability explain the contribution of phenolic compounds to organoleptic properties of the Pomegranates. Nevertheless, according to Gil et al. [9], phenolic compounds are connected to environmental factors, varieties, growing season, postharvest storage conditions and processing procedures. As the cultivars of this study have been grown in the same germplasm, it can be concluded that the organoleptic properties of the Pomegranates studied, like the juice color and the taste were obviously closely connected to the cultivar type or/and ripening season. Further research is needed to investigate which factors may be responsible for the organoleptic properties of the Pomegranates.

According to the current study, it can be concluded that the most appreciated juices were not the most beneficial to health while the fruit size could have a relationship with the beneficial effects of pomegranate on health. To our knowledge, no work relates the consumer acceptability to the antioxidant capacity of the pomegranate. Meanwhile, bitterness in plant foods has been described as a sensory defect with a major economic effect. Responding to taste-driven consumer demand, the food industry generally debittering plant food what improves the taste, but reduces the beneficial effects on health [23]. To avoid these problems, it can be suggested the consumption of cultivars with high concentration of polyphenols, and high antioxidant properties and reduction of the bitterness by addition of sugar, such as in the case of wines. The addition of sugar is a relatively inexpensive option to mask the bitterness while preserving the bioactive potential of the polyphenols. However, further studies should be undertaken to elucidate the duality product acceptability and health benefits.

\section{Conclusions}

The frequency of respondents to the questionnaire showed that three of seven of the participants eat Pomegranate as fresh fruit and that the size of the fruit, the taste and the color of the aril were the main criteria for participants to select Pomegranate. This study also found that the taste of the pomegranate juices was inversely related to their TA. In addition, the juices studied appeared to have a great variability in terms of TPC, CTC, TFC and TAC, as well as, for the antioxidant capacities. PLS regression revealed that the juices most appreciated by participants were not the most beneficial to health. However, a significant correlation was found between the fruit size acceptability and the antioxidant capacity of the Pomegranate, so, a relationship could be established between the size of the Pomegranate and its health benefits.

By limiting the climatic and edaphic influences, as well as, the horticultural practices by collecting the pomegranates 

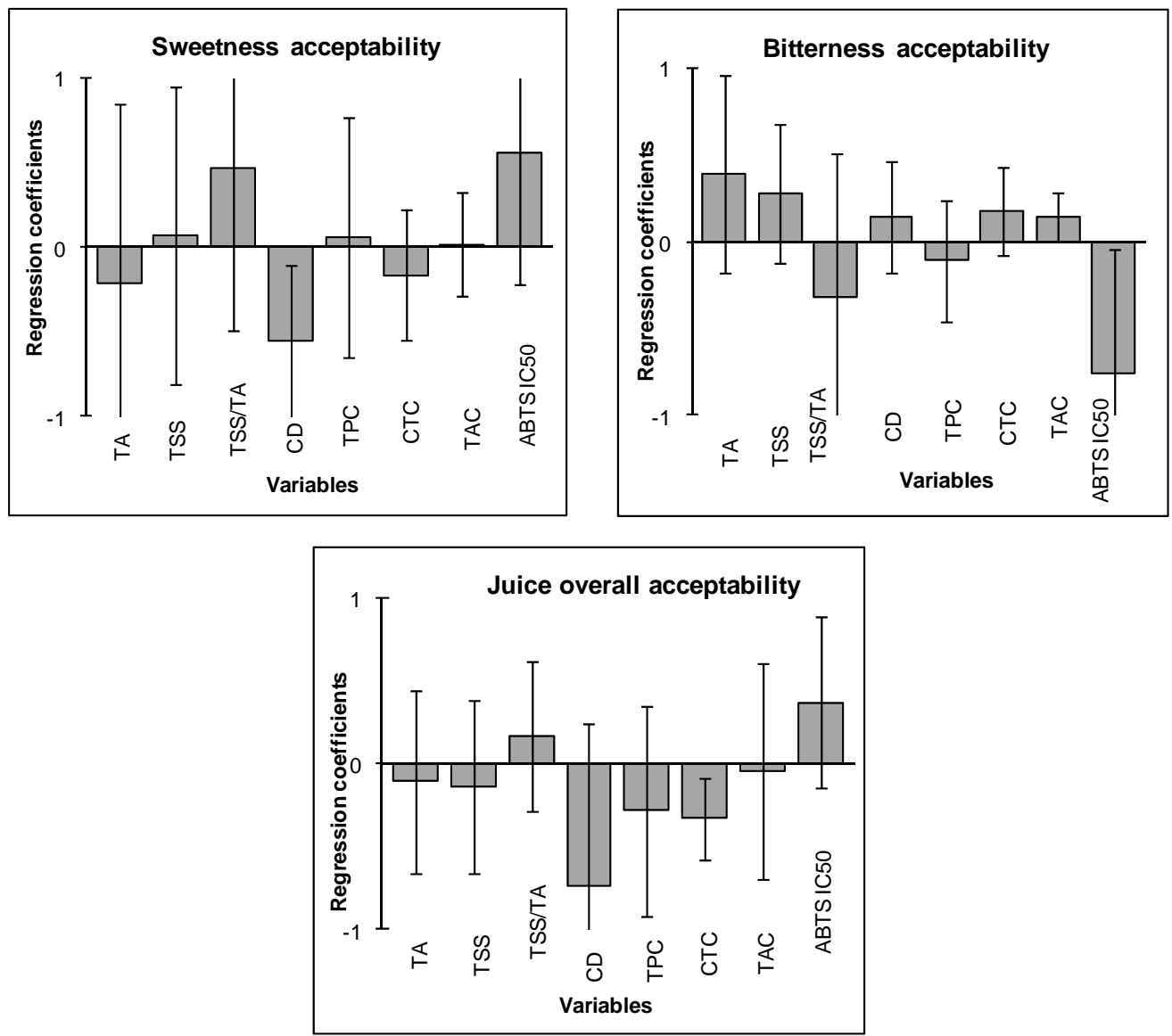

Figure 4. 95\% Jack-knife confidence intervals of the Partial Least Squares regression coefficients in the Partial Least Squares regression of sweetness, bitterness and juice overall acceptability on instrumental analyses (Variables with confidence interval includes the value 0 are significant $(\mathbf{p}<0.05)$; TSS $=$ Total Soluble Sugars expressed as degrees Brix $\left({ }^{\circ} \mathrm{Brix}\right)$; TA $=$ Titratable Acidity expressed as pourcent of malic acid (\% MA); TSS/TA $=$ sugars to acidity ratio; $\mathrm{CD}=\mathrm{Color}$ Density; TPC $=$ Total Phenolic Content expressed as mg gallic acid equivalent per liter of juice $(\mathrm{mg}$ GAE/L); TFC = Total Flavonoids Content expressed as mg quercetin equivalent per liter of juice $(\mathrm{mg} \mathrm{QE} / \mathrm{L})$; TAC $=$ Total Anthocyanins Content expressed as mg cyaniding-3-glucoside equivalent per liter of juice (mg CGE/L); CTC $=$ Condensed Tannins Content expressed as mg catechin equivalent per liter of juice $(\mathrm{mg} \mathrm{CE} / \mathrm{L}) ; \mathrm{ABTS} \mathrm{IC}_{50}=$ radical scavenging capacity on $\mathrm{ABTS}$ radical expressed as concentration of the extract required to reduce $50 \%$ of the initial ABTS free radical).

from the same site, it can be concluded that the observed differences in terms of phenolic contents and organoleptic properties of the pomegranate juices studied depend on cultivar type or/and ripening season. Although the primary function of food is to provide nutrients, its secondary function concerns organoleptic properties such as taste and its tertiary function is to prevent disease. However, results of this study appeared that the secondary and tertiary functions are linked.

The results of this study could be used to understand the complex nature between the acceptability of a product, as perceived by untrained subjects, and its benefits on health.

\section{Acknowledgements}

The authors are grateful for the subjects who participated in the acceptability tests. They also kindly thank Miss Amina BARKHALLAH for proof reading the English version of this manuscript.

\section{REFERENCES}

[1] S. J. Kays, "Preharvest Factors Affecting Appearance," Postharvest Biology and Technology, Vol. 15, No. 3, 1999, pp. 233-247. doi:10.1016/S0925-5214(98)00088-X

[2] H. M. Merken and G. R. Beecher, "Measurement of Food Flavonoids by High-Performance Liquid Chromatography-A Review," Journal of Agricultural and Food Chemistry, Vol. 48, No. 3, 2000, pp. 577-599. doi:10.1021/jf9908720

[3] B. N. Ames, "Dietary Carcinogens and Anticarcinogens: Oxygen Radicals and Degenerative Diseases," Science, Vol. 221, No. 4617, 1983, pp. 1256-1263. 
doi:10.1126/science.6351251

[4] B. Winkel-Shirley, "It Takes a Garden. How Work on Diverse Plant Species Has Contributed to an Understanding of Flavonoid Metabolism," Journal of Plant Physiology, Vol. 127, No. 4, 2001, pp. 1399-1404.

[5] F. Shahidi and M. Naczk, "Phenolics in Food and Nutraceuticals: Sources, Applications and Health Effects," CRC Press, Boca Raton, 2004.

[6] M. Özgen, C. K. Durgac, S. Serc and C. Kaya, "Chemical and Antioxidant Properties of Six Pomegranate Cultivars Grown in the Mediterranean Region of Turkey," Food Chemistry, Vol. 111, No. 3, 2008, pp. 703-706. doi:10.1016/j.foodchem.2008.04.043

[7] E. Sepúlveda, C. Sáenz, A. Peña, P. Robert, B. Bartolomé and C. Gómez-Cordovés, "Influence of the Genotype on the Anthocyanin Composition, Antioxidant Capacity and Color of Chilean Pomegranate (Punica granatum L.) Juices," Chilean Journal of Agricultural Research, Vol. 70, No. 1, 2010, pp. 50-57. doi:10.4067/S0718-58392010000100005

[8] N. Seeram, R. N. Schulman and D. Heber, "Pomegranates: Ancient Roots to Modern Medicine," CRC Press/Taylor and Francis, Boca Raton, 2006.

[9] M. I. Gil, F. A. Tomas-Barberan, B. Hess-Pierce, D. M. Holcroft and A. A. Kader, "Antioxidant Activity of Pomegranate Juice and Its Relationship with Phenolic Composition and Processing," Journal Agriculture Food Chemistry, Vol. 48, No. 10, 2000, pp. 4581-4589. doi:10.1021/if000404a

[10] P. Melgarejo, D. M. Salazar and F. Artés, "Organic Acids and Sugars Composition of Harvested Pomegranate Fruits," European Food Research and Technology, Vol. 211, No. 3, 2000, pp. 185-190. doi:10.1007/s002170050021

[11] M. Mars, "Ressources Génétiques du Grenadier (Punica granatum L.) en Tunisie: Propspection, Conservation et Analyse de la Diversité," Thèse de Doctorat es Sciences Naturelles, Faculté des Sciences de Tunis, Université El-Manar, Tunisie, 2001.

[12] S. H. Mirdehghan and M. Rahemi, "Seasonal Changes of Mineral Nutrients and Phenolics in Pomegranate (Punica granatum L.) Fruit," Journal of Scientia Horticulturae, Vol. 111, No. 2, 2007, pp. 120-127. doi:10.1016/i.scienta.2006.10.001

[13] M. Meilgaard, G. V. Civille and B. T. Carr, "Sensory Evaluation Techniques," 2nd Edition, CRC Press, Boca Raton, 1991, pp. 354.

[14] H. J. H. MacFie, N. Bratchell, K. Greenhoff and L. Vallis, "Designs to Balance the Effect of Order of Presentation and First-Order Carry-Over Effects in Hall Tests," Journal of Sensory Studies, Vol. 4, No. 2, 1989, pp. 129-148. doi:10.1111/j.1745-459X.1989.tb00463.x

[15] S. Georgé, P. Brat, P. Alter, and M. J. Amiot, "Rapid Determination of Polyphenols and Vitamin C in Plant-Derived Products," Journal Agriculture Food Chemistry, Vol. 53, No. 5, 2005, pp. 1370-1373. doi:10.1021/jf048396b

[16] A. Arvouet-Grand, B. Vennat, A. Pourrat and P. Legret,
"Standardisation d'un Extrait de Propolis et Identification des Principaux Constituants," Journal de Pharmacie de Belgique, Vol. 49, No. 6, 1994, pp. 462-468.

[17] G. W. Cheng and P. J. Breen, "Activity of Phenylalanine Ammonialyase (PAL) and Concentrations of Anthocyanins and Phenolics in Developing Strawberry Fruit," American Society for Horticultural Science, Vol. 116, No. 5, 1991, pp. 865-869.

[18] M. L. Price, S. Van Scoyoc and L. G. Butler, "A Critical Evaluation of the Vanillin Reaction as an Assay for Tannin in Sorghum Grain," Journal Agriculture Food Chemistry, Vol. 26, No. 5, 1978, pp. 1214-1218. doi:10.1021/jf60219a031

[19] R. Re, N. Pellegrini, A. Proteggente, A. Pannala, M. Yang and C. Rice-Evans, "Antioxidant Activity Applying an Improved ABTS Radical Cation Decolorization Assay," Free Radical Biology and Medicine, Vol. 26, No. 9-10, 1999, pp. 1231-1237. doi:10.1016/S0891-5849(98)00315-3

[20] M. O’Mahony, “Sensory Evaluation of Food: Statistical Methods and Procedures," Marcel Dekker, New York, 1986.

[21] I. T. Jolliffe, "Principal Component Analysis," 2nd Edition, Springer, 2002, $487 \mathrm{p}$.

[22] M. A. Marlette, S. B. Templeton and M. Panemangalore, "Food Types, Food Preparation, and Competitive Food Purchases Impact School Lunch Plate Waste by SixthGrade Students," Journal of the American Dietetic Association, Vol. 105, No. 11, 2005, pp. 1179-1182. doi:10.1016/j.jada.2005.08.033

[23] R. L. Rouseff, "Bitterness in Food Products: An Overview," In: R. L. Rouseff, Ed., Bitterness in Foods and Beverages. Developments in Food Science, Elsevier, Amsterdam, Vol. 25. 1990, pp. 1-14.

[24] F. Karadeniz, "Main Organic Acid Distribution of Authentic Citrus Juices in Turkey," Turkish Journal of Agriculture and Forestry, Vol. 28, No. 4, 2004, pp. 267-271.

[25] H. Borochov-Neori, S. Judeinstein, E. Tripler, M. Harari, A. Greenberg, I. Shomer and D. Holland, "Seasonal and Cultivar Variations in Antioxidant and Sensory Quality of Pomegranate (Punica granatum L.) Fruit," Journal of Food Composition and Analysis, Vol. 22, No. 3, 2009, pp. 189-195. doi:10.1016/j.jfca.2008.10.011

[26] L. Shaked-Sachary, D. Weiss, M. Reuveni, A. NissimLevi and M. Oren-Shamir, "Increased Anthocyanin Accumulation in Aster Flowers at Elevated Temperatures Due to Magnesium Treatment," Plant Physiology, Vol. 114, No. 4, 2002, pp. 559-565. doi:10.1034/j.1399-3054.2002.1140408.x

[27] O. Tibe, J. O. Amarteifio and R. M. Njogu, "Trypsin Inhibitor Activity and Condensed Tannin Content in Bambara Groundnut (Vigna subterranean L. verde) Grown in Southern Africa," Journal of Applied Sciences and Environmental Management, Vol. 11, No. 2, 2007, pp. 159164.

[28] G. Mousavinejad, Z. Emam-Djomeh, K. Rezaei and M. H. H. Khodaparast, "Identification and Quantification of Phenolic Compounds and Their Effects on Antioxidant Ac- 
tivity in Pomegranate Juices of Eight Iranian Cultivars," Food Chemistry, Vol. 115, No. 4, 2009, pp. 1274-1278.

[29] L. J. Porter, L. N. Stich and B. G. Chan, "The Conversion of Procyanidins and Prodelphinidins to Cyaniding and Delphinidin," Phytochemistry, Vol. 25, No. 1, 1986, pp. 223-230.

[30] R. Tzulker, I. Glazer, I. Bar-Ilan, D. Holland, M. Aviram and R. Amir, "Antioxidant Activity, Polyphenol Content and Related Compounds in Different Fruit Juices and Homogenates Prepared from 29 Different Pomegranate Accessions," Journal of Agricultural and Food Chemistry, Vol. 55, No. 23, 2007, pp. 9559-9570.
[31] M. Zampini, E. Wantling, N. Phillips and C. Spence, "Multisensory Flavor Perception: Assessing the Influence of Fruit Acids and Color Cues on the Perception of FruitFlavored Beverages," Food Quality and Preference, Vol. 19, No. 3, 2008, pp. 335-343.

[32] J. W. Fahey, Y. Zhang and P. Talalay, "Broccoli Sprouts: An Exceptionally Rich Source of Inducers of Enzymes That Protect against Chemical Carcinogens," Proceedings of the National Academy of Sciences of the United States of America, Vol. 94, No. 19, 1997, pp. 10367-10372. 